\title{
Integrating Language and Content: A Case Study
}

Stephen Dunbar

This article addresses the question of how language and content can be taught concurrently. It approaches the question from a perspective of task: examining what it is that a student needs to know about an academic task to perform effectively in a specific situation. In other words, how a general knowledge of the requirements of a given task relates to performance on a specific task. To illustrate this, a case study of summarizing is presented.
The case study suggests that a metacognitive awareness of the general requirements has an impact on student performance. In addition, it illustrates how this awareness impacts on the linguistic performance of students. Use of the Knowledge Framework (Mohan, 1986), which involves the use of visuals to link the general requirements of a task to a specific situation, is suggested as a possible way of co-ordinating the teaching of language and content.

This paper examines one way of integrating language and content. It explores this topic by using a case study, from an English class, to demonstrate a way of helping students more successfully perform the task of summary writing. To help students do this successfully, it is suggested that the teacher must have an understanding of what is involved in summary writing, an understanding of how language is used to convey this information, and an understanding of how students can be supported in the performance of the task.

\section{THE EXAMPLE}

To illustrate this, a sample of a student's work will be used. The student was in a regular secondary English class designed for students who had been identified as having limited English proficiency. The student produced the following piece of writing to summarize a video, Where's Winston, which they had viewed in class:

The video was taken in North America and in this movie there were some really important characters they were Winston, Wayne, Lyanne, Mother, Sean the story starts by Winston shooting Sean in the theatre. He was teased by Sam he asked Winston for money and he gave it to Sam then later on Wayne comes along and talks to him in Chinese and becomes his friend. 
Before examining this piece on written discourse for its linguistic features, such as sentence structure, tense sequence, cohesion, and spelling, it is important to assess what it is that this student does and does not know about the task of summary writing.

In order to successfully complete the task of summary writing the student must:

- have a general awareness of what a summary is:

- its parts

- how the parts are put together

- why the parts are organized in this way

- how such a writing is evaluated

- be able to relate that general knowledge to a specific story/situation by:

- selecting specific, salient, facts

- deciding which parts of the summary the facts will appear

- deciding how the writing will be ordered

- selecting the best language at his/her disposal to express the information

- and finally be able to evaluate how well his specific piece of writing reflects what the writing should look like.

Examining the student's writing from this perspective it would appear that the student:

- has limited general knowledge of what a summary is;

- is unable to make appropriate judgements to organize the information;

- is attending to so many aspects of the task that language becomes a minor factor in the overall execution of the task.

This form of analysis helps clarify what demands the task of "summary writing" has placed on this student. However, the question still remains as to whether alerting the student to these aspects will enable him to cope more effectively with the task.

To answer this question, the student was supplied with a visual, shown in Figure 1, which he could use as a form of scaffolding to hold on to while performing the linguistic gymnastics that the task required. In addition, the visual would hopefully link the general knowledge required of a summary writing task to the specific situation. It was hoped that this would help the student to see 
what, in general, was needed, why it should be there, how language could be used to show sequence and cause/effect relationships, and how this was related to writing a summary of the video.

\section{FIGURE 1}

\section{Where's Winston: Summary}

INTRODUCTION:

TITLE:

PLOT:

PLACE:

TIME:

CHARACTERS:

BODY:

\begin{tabular}{||l||l|l|l||}
\hline WHAT HAPPENS & $\begin{array}{l}\text { WHAT HE } \\
\text { DOES }\end{array}$ & $\begin{array}{l}\text { WHAT HE } \\
\text { COULD/SHOULD } \\
\text { HAVE DONE }\end{array}$ & RESULT \\
\hline \hline $\begin{array}{l}\text { TEASED/LOW } \\
\text { MARKS }\end{array}$ & & & \\
\hline $\begin{array}{l}\text { INVITED OUT } \\
\text { GIVEN GIFIS }\end{array}$ & & & \\
\hline $\begin{array}{l}\text { ASKED TO BEAT } \\
\text { UP RESTAU- } \\
\text { RANT OWNER }\end{array}$ & & & \\
\hline $\begin{array}{l}\text { ASKED TO } \\
\text { SHOOT RIVAL } \\
\text { GANG MEMBER }\end{array}$ & & & \\
\hline
\end{tabular}

CONCLUSION:

AT WHAT POINT SHOULD WINSTON HAVE TAKEN CONTROL?

SUGGEST HOW HE COULD HAVE DONE THIS:

The following writing sample, by the same student, written the day after the initial writing, shows the effect that the visual, along with the heightened metacognitive awareness of the task of summary writing, had on his ability to perform the task: 
Where's Winston is about a boy who gets pulled into a gang. It happened in Vancouver in 1986, and later on a movie was made about it. The characters of this movie are Winston, Lyanne, Wayne, and Sean.

In the beginning Winston was getting low marks and was teased by Sean. He didn't do anything about improving his marks or seek any kind of help. Winston was extorted by Sean and Tommy and he gave them money. He was not supposed to give them money. Wayne was a gang member, who was watching Winston from the very beginning because he wanted to recruit Winston in his gang. (excerpt only, the summary continues)

The second writing indicates that the heightened metacognitive awareness, combined with the visual, had a significant impact on the student's ability to write a summary. The metacognitive awareness acted as a beginning for the student to better understand what summary writing involves. The visual enabled the student to hold enough information steady so that he was able to focus attention on the language that he had at his disposal for expressing what he knew.

\section{THE USE OF VISUALS}

The use of visuals to help students relate the general nature of a task to its application in a specific situation and to examine how language is used to express this is based on Mohan's $(1986,1989)$ Knowledge Framework, which is a model for integrating the teaching of language and content. Mohan (1986) argues that "it is absurd to ignore the role of content in the language class, just as it is absurd to ignore the role of language as a medium of learning in the content class" (p. iv).

The use of visuals is one way to support students while they learn both language and content. It is an alternative to adjunct courses which attempt to parallel content courses by teaching the language associated with the content. It is also an alternative to code-focused teaching. Learning about a language is not the same as learning a language. Saville Troike (1984) supports this by suggesting that accuracy at the syntax level makes little difference in academic achievement. Her data analysis indicate that the correlation between reading achievement and control of syntax is only .025 .

The Knowledge Framework (Mohan 1986) suggests that analyzing academic tasks and determining what learning strategies are needed, 
can be done most effectively within the context that the task is performed. Once strategies are divorced from a social context, which in this case is academic, meaning and the role of language in acquiring meaning are adversely affected. The Knowledge Framework offers insight for analyzing a task from this perspective.

Take, for example, a task such as reading a short story. The Knowledge Framework suggests that what makes such a task demanding or undemanding may have a lot to do with the performer's familiarity with the type of task he or she is being asked to perform. This is addressed by Schmidt (1990) when he proposes a distinction between controlled and automatic processing. The more automatic a process is, the less demanding it becomes. The more controlled a process is, the more demanding it becomes. A student's background knowledge, not necessarily specific knowledge, but knowledge of performing certain types of tasks, may, therefore, impact on how well he or she is able to perform on a given task. If students are not aware of story structure, and are not able to make predictions based on organizational features of a story, the task of reading a short story will be demanding. If, however, students are aware that a visual, such as the one shown in Figure 2, is a skeletal representation of all short stories, the demands of the task may be decreased.

\section{FIGURE 2}

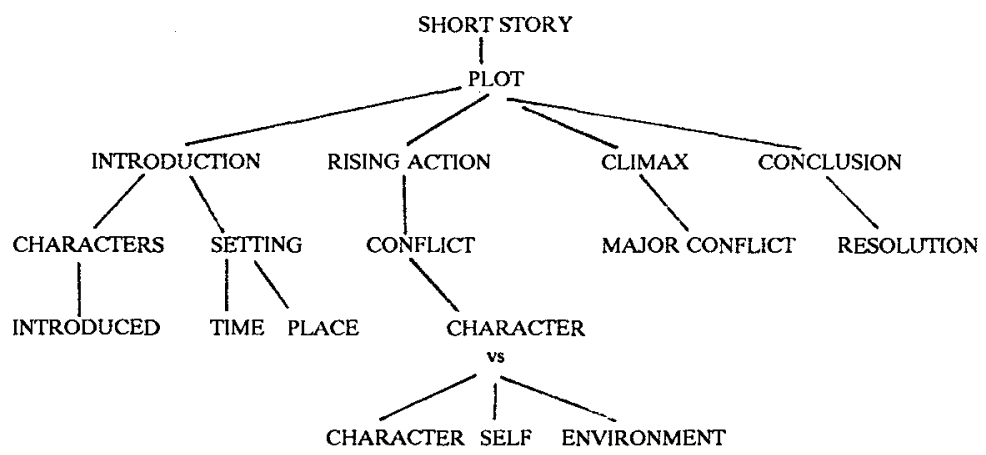

In addition, the Knowledge Framework suggests that learners need to consider how a specific short story follows this generic grid, by actively making connections between specific information and 
relating it to a general bank of knowledge, as well as drawing on their general knowledge and applying it to a variety of specific situations. As Mohan (1986) says, "the main contrast in the organizing framework is between general, theoretical knowledge and specific, practical knowledge" (p. 40).

This is a particularly important concept. If students view the reading of each short story, poem, play, the performance of each science experiment, or description of a governmental system as a totally new experience, bearing no connection to what they have read, heard, or seen before, they will have a limited basis on which to generalize what they have "learned" to new situations.

\section{DISCUSSION}

As the description of the Knowledge Framework and the case study demonstrate, alerting students to what a task involves can be beneficial. By using the Knowledge Framework to analyze a task and develop a visual to support students while performing the task, it is possible to make better use of students' prior knowledge, help them apply this knowledge to new situations, make specific connections between language and content, and at the same time continually add to the students' background knowledge for use in future tasks.

It is interesting to note the impact that this form of analysis has on linguistic performance. In the case study, the student's first attempt at summary writing indicates that, linguistically, the student had a minimal concept of what a sentence was. Yet, when given assistance, in the form of a visual, this no longer appears to be true. Apparently, when the student was trying to perform all aspects of the task at once, linguistic structure was lost in the shuffle. There was so much for the student to attend to that no one aspect for the task was performed well.

This suggests that the teaching of language and content can better be conceptualized from the perspective of task, when task is analyzed from both a content and linguistic perspective by using the Knowledge Framework. It is a way of integrating the learning strategies that Willing (1987) suggests, and a way of determining what aspects of a task are, for a given student, automatic or controlled. In addition, it offers a way of enabling students to move from controlled processing to automatic processing by increasing their background knowledge.

Central to this is the use of visual organizers to help students "see" what is involved. From a teaching perspective, a visual allows 
for language input through discussion of various ways of expressing what is shown in a visual, how ideas can be combined, how expression can begin and end at various points on the visual, and allows students to test out and share with their classmates various forms of discourse. Students, therefore, supply a great deal of the input for each other.

To illustrate this, suppose students had access to the following information:

TITLE:

PLOT:

TIME:

PLACE:
Where's Winston

A young boy is recruited into a gang

Present

Vancouver

CHARACTERS: Winston, his family, his friends

and were asked to suggest a variety of ways of putting this information into sentences. Those students with limited proficiency might produce the following:

The title of the story is Where's Winston. The plot is a young boy is recruited into a gang. The time is the present. The place is Vancouver. The characters are Winston, his family, his friends.

which is little more than a transformation of the suggested pieces of information into sentences. On the other hand, those students with more proficiency might produce something like the following:

Where's Winston is a story that takes place in Vancouver in the 1990's and is about a young boy who gets involved in a criminal youth gang. The main character in the story is Winston. Other important characters are his family, and the people at his school that involve him in the gang.

As students produce and share various ways of expressing information in written form, via writing their versions on overheads, on the blackboard, or by sharing their work in small groups, they are exposed to a greater variety of ways that information can be organized. Also, the varieties are a product of their own doing, and therefore are more likely to match the linguistic and cognitive development of the group. In addition, regardless of the organizational pattern chosen by individual students, all students will likely produce a "successful" piece of written discourse. 


\section{CONCLUSION}

As this case study and the discussion suggest, there are ways of integrating the teaching of language and content. Specifically, the use of the Knowledge Framework, used as a tool to analyze task, and the use of visuals to help students organize content and language, is one way. However, more research, with larger numbers of students, who operate at a variety of levels of language proficiency, and who need to learn in a variety of content subject areas, is needed to determine the extent to which this method of integrating the teaching of language and content can be applied to a wider range of classroom tasks to support students' learning. In addition, further research is required to find out what impact this method might have on the length of time students need to spend in order to learn to cope successfully with academic subject matter, which, at present, Cummins (1986) and Collier (1989) suggest can take upwards of 5 to 10 years.

\section{AUTHOR}

Stephen Dunbar is a teacher with the Vancouver School Board, Vancouver, B.C. He has worked with the development of materials at both the school and district level to help teachers coordinate the teaching of language and content. In addition to working with the Vancouver School Board, his experience includes teaching English overseas, working in the area of teacher training, and teaching ESL at various levels, from elementary age students to adults.

\section{REFERENCES}

Collier, V. P. (1989). How Long? A synthesis of research on academic achievement in a second language. TESOL Quarterly, 23 509-531.

Cummins, J. (1986). Language proficiency and academic achievement. In J. Cummins and M. Swain, Bilingualism in Education, (pp. 138-161). London: Longman.

Mohan, B. A. (1986). Language and content. Reading, MA: Addison Wesley.

Mohan, B. A. (1989). Knowledge structures and academic discourse. Word, 40, 1.2, 99-114. 
Saville Troike, M. (1984). What really matters in second language learning for academic achievement? TESOL Quarterly, 18, 199219.

Schmidt, R. (1990). The role of consciousness in second language learning. Applied Linguistics, 11(2), 129-158.

Where's Winston? (1980). Ministry of Attorney General. Province of British Columbia: Public Legal Education Society.

Willing, K. (1987). Learning strategies as information management. Prospect, The Journal of the Adult Migrant Education Program, 2(3), 273-291. 